\title{
CHINA'S MISSION IN SURVEYING，MAPPING AND GEOGRAPHIC INFORMATION DURING GLOBAL GOVERNANCE
}

\author{
Jia Dan Xue Chao Chen Xi \\ Development Research Center for Surveying \&Mapping, National Administration of Surveying Mapping \& Geoinformation, Beijing \\ 100830 jiadan@sbsm.gov.cn
}

KEY WORDS:Global Governance, Global Geographic Information Resource, Public Goods, Scientific and Technological Assistance

\begin{abstract}
:
In the new era, it is proposed that China should be transformed from a participant and a cooperator into a designer, an impeller and a leader, continue taking an effect of responsible great power, increase public product supply, perfect a global governance system and contribute to China's wisdom and China's schemes during global governance, thus surveying and mapping geographic information takes on great mission. On the one hand, we have to timely grasp global geographic information data resources to provide an important scientific data support for China's wisdom and China's schemes. On the other hand, we have to provide surveying and mapping geographic information infrastructure construction and public products for developing countries, support location services within a global territorial scope, and realize the smoothness of talent flow, material flow and information flow between China and countries in the world. Meanwhile, external assistance and international communication and cooperation of surveying and mapping geographic information are also enhanced, and popularization and application of a geographic information technology in underdeveloped countries and regions are promoted.
\end{abstract}

\section{PREFACE}

In the new era, China is transforming from a participant and a cooperator into a designer, an impeller and a leader, continue taking an effect of responsible great power, increase public goods supply, build a sophisticated global governance system and deliver China's wisdom and China's schemes during global governance, thus surveying and mapping geographic information takes on great mission.

\section{IN THE FIELD OF GLOBAL ECONOMIC GOVERNANCE, MAPPING AND GEOGRAPHICAL INFORMATION BEAR AN IMPORTANT MISSION IN PROMOTING THE CONSTRUCTION OF THE "BELT AND ROAD"}

In the field of global economic governance, Chinese President $\mathrm{Xi}$ Jinping launched an important cooperation initiative of building the Silk Road Economic Belt and the 21st Century Maritime Silk Road" in 2013. The "Belt and Road" initiative is not only a great innovation in China's active participation in global economic governance and its mechanism reform, is a creative wisdom to promote the process of Globalization, is also a common platform that is provided by China in order to promote global economic development and achieve production capacity complementation and strategic linking.

In March 2015, the State Development and Reform Commission, the Ministry of Foreign Affairs and the Ministry of Commerce jointly issued the "vision and action of promoting the common construction of the Silk Road Economic Belt and the 21st Century Maritime Silk Road" (Vision and Action). According to the deployment of Vision and Action, the "Belt and Road"construction will focus on communication in policy, infrastructure unicom, trade open, financial intermediation and people-to-people links, with the six main economic corridors of China-Mongolia-Russia, New Eurasian Continental Bridge, China-Central Asia-West Asia, China-Indo-China Peninsula, China-Pakistan, Bangladesh-China-India-Myanmar as the main frame, it will overall realize the regional political, economic, security, cultural, and an omnibearing win-win cooperation and create a common responsibility community, common destiny community for development and prosperity. Surveying and mapping geographical information is an important part of participating in the construction of the "Belt and Road", geographic information resources service is the basis of realizing the policy communication, infrastructure unicom, trade open, financial intermediation, and people-to-people links with the countries along the "Belt and Road". It is also the guarantee for promoting major actions and important projects of the "Belt and Road". At present, with the increasing number of cooperation areas between China and countries along the "Belt and Road", the demands and requirements for surveying and mapping of geographic information have become increasingly prominent and urgent.

\subsection{Construction of the "Belt and Road" needs basic} geographic information resources to provide protection

The "Belt and Road" construction involves many countries and regions. With the advancement of the "Belt and Road", the talent flow, material flow, information flow, capital flow, and knowledge flow between China and these countries have also become increasingly widespread. As of September 2016, within three years, non-financial investments by Chinese companies in the areas along the "Belt and Road" have reached 51.1 billion U.S. dollars and the project contracting scale has reached more than 200 billion U.S. dollars. The related strategic planning, emergency, and construction of these projects urgently require the autonomous provision of location services on a global scale. Unimpeded information is the key to the construction of the 
"Belt and Road". China has proposed that after 10 years' efforts, we will basically build the "Belt and Road" spatial information corridor. As the framework and important construction content of the information corridor, basic geographic information resources urgently need to be accelerated.

\subsection{The safe operation of the "Belt and Road" needs basic} geographic information resources to provide basic support

The "Belt and Road" is a long-term and systematic project. With the advancement of the "Belt and Road" Initiative, it urgently requires a set of geographic information data to provide rigid support to integrate the five areas of policy communication, road connectivity, trade flow, currency circulation, and people-to-people cooperation into one platform. We must consider the resource endowments, population resources, and regional radiation capabilities of the countries where they are located. We need to accurately cooperate, seize the key channels, nodes and projects, guide the planning, construction and management of related projects with integrated thinking, and enhance the risk control capabilities of the countries along the route. Along the "Belt and Road" area where there are many tribes, complex terrain, various contradictions, the threats of terrorist threats, large-scale mass incidents, major natural disasters, and environmental security threats have continued to increase.To maintain international security and order, it is also urgent to master basic geographic information resources and provide modern, information-based means for effectively responding to various types of non-traditional threats.

\section{GLOBAL PUBLIC CRISIS GOVERNANCE}

\section{URGENTLY NEEDS MAPPING AND GEOGRAPHIC INFORMATION TO PROVIDE SUPPORT AND \\ GUARANTEE}

In the field of global public crisis management, currently, global challenges have been increasingly emerging, global economy continues to be in a downturn and the gap between the rich and the poor is continuously widening, threat factors such as global terrorism and regional turmoil, which affect international security, are gradually in diversity, and ecological crisis and other human sustainable development problems are more prominent. Under this background, China actively participates in global public crisis management. In order to provide China's wisdom and China's schemes to deal with global resource and energy security, food security, network information security, climate change, fight terrorism, prevent significant infectious diseases, deal with great natural disasters, strengthen environmental protection monitoring and the like, we must timely grasp global geographic information data and provide scientific data support for accurately grasping the world situation and enhancing an ability to control global affairs.

At present, Beidou will be the first to cover the "Belt and Road" countries in 2018 and cover the world by 2020. As the world's fourth-largest satellite navigation system, the Beidou satellite navigation system is compatible with other satellite navigation systems of the world and can provide high-precision, highly reliable positioning, navigation, and timing service. It has the combined service features of navigation and communication. The Beidou system is not only the "China's Beidou" but also "world's Beidou". In order to make the rapid development of the BeiDou satellite navigation system to benefit more and more people around the world, it needs to accelerate the construction of the ground infrastructure and surveying and mapping geographic information public products Particularly, it is necessary to provide mapping and geographic information infrastructure construction and public products for countries along the "Belt and Road" roadmap, support location services in the global geographic area, and achieve the smooth flow of talent, material, and information between China and other countries all over the world. Currently, Beidou has conducted demonstration and promotion work based on high-precision navigation and location services of Beidou in Indonesia, Laos, Malaysia, Pakistan, Thailand, Iran and other countries, which has been recognized by many countries in the Asia-Pacific region.

At the same time, China's mapping and geo-information related technologies are stepping up to catch up with the world's advanced level. Beidou navigation, satellite remote sensing, and "Tiandi Map" network services and other facilities have been continuously improved, and related applications have continued to be extensive and in-depth, and they have emerged in the international arena. China has fully realized localization in the fields of aeronautical digital cameras, unmanned aerial vehicle aerial camera systems, emergency monitoring systems, mobile measurement systems, and geographic information platform software, and some of its functions and performance indicators are superior to similar foreign products.

At present, the continuous integration of domestic geographic information equipment technology with big data, cloud computing, and artificial intelligence has produced a new form of service, which plays an important role in solving and improving people's livelihood. With the global coverage of the Beidou system and its adoption by neighboring countries, it is imperative to promote and apply geographical mapping information equipment technologies to promote the construction of digital cities and wisdom cities in the world, enhance its position service capabilities and promote its application in medical, education, food safety, water security, public safety, mobile travel, environmental protection, agricultural production and other fields. In the process of popularizing the Beidou and Earth Observation System to China's neighboring countries and regions, a huge industrial chain will be formed, thus forming a huge impetus to the economic development of surrounding countries and regions.

\section{SPECIFIC MEASURES FOR MAPPING}

\section{GEOGRAPHIC INFORMATION TO PARTICIPATE IN} GLOBAL GOVERNANCE

\subsection{Accelerate the acquisition of global basic geographic information resources and provide support for global governance}

Currently, the construction of basic geographical information resources in countries and regions along the "Belt and Road" has accelerated. However, it is also necessary to clarify the construction priorities. The first step is to focus on the overall deployment of the "Belt and Road", carry out the construction of satellite data acquisition sources and consolidate the ability to acquire global geographic information resources. It is necessary to master the geographic information resources in key regions such as the countries along the six major economic corridors of the "Belt and Road" and to form the basic support 
capabilities for the "Belt and Road" project construction, abroad geological survey, military and diplomacy applications. The second step should be based on the needs of the country, select key global regions for high-precision geographic information resources to make the ability to apply the global geographic information resources to the international advanced level. At the same time, we need to accelerate and enhance the global geographic information resource service capabilities and strengthen the researches on related standards and key technologies for products, services and applications.

\subsection{Vigorously promote the "go out" of surveying and mapping geographic information equipment}

At present, based on the China-proposed SCO, the "Belt and Road" initiative advocated by China, and China's strategic cooperation partnership with ASEAN for more than 10 years, and other multilateral bilateral cooperation mechanisms,the exchanges and cooperation between China and other countries in the aspects of resources, environment, ecology, and geographical information resources have been continuously deepened. For example, in the Tashkent Declaration of the 15th Anniversary of the Establishment of the Shanghai Cooperation Organization released in June 2016, the government mentioned "measures to ensure stable social and economic growth, improve people's well-being and living standards, it is important to further deepen cooperation in trade, production capacity, finance, investment, agriculture, customs, communications, satellite navigation and other areas of common interest." This fully shows that the mapping and geographic information related technology represented by satellite navigation has become a key cooperation area between China and other countries. Therefore, we can consider making full use of these platforms, encourage and support domestic surveying and mapping geographic information enterprises to participate in international competition, and vigorously promote autonomous technologies of our country such as satellite navigation, satellite remote sensing, geographic information network services, and equipment manufacturing to be carried out in other countries, especially those along the "Belt and Road", nurturing the international competitiveness of China's independent technologies and industries, and focusing on building a new order for international geographic information technology and market, and promoting the "go out" of geographical information for surveying and mapping. Specific measures include fully utilizing China-Asia-Europe Expo, Asia-Europe Commodities Trade Fair, China-South Asia Expo, China-ASEAN and other large-scale international exhibitions as well as some overseas exhibition platforms, relevant departments, actively organizing our country's surveying and mapping geographic information enterprises to participate in the exhibitions, and display our mapping and geographic information technology equipment in an all-round way.

\subsection{Increase the geographic information assistance to countries and regions along the "Belt and Road"}

According to the Asian Economic Integration Report 2015 issued by the Asian Development Bank, China's share of high-end technology products in Asia accounted for 43.7\%, ranking first in Asia, the high-end technology products represented by high-speed rail, nuclear power and navigation satellite systems are highly recognized by Asian countries. So far, under the vigorous promotion of the relevant departments in China, Beidou "going out" has already blossomed. In Indonesia, Laos, Malaysia, Pakistan, Kampuchea, Brunei, Thailand, Iran and other countries, the demonstration and promotion of high precision navigation and location service based on the Beidou is carried out,which has increased its influence in the international arena and it has become another gorgeous business card representing the overall strength of China's science and technology.

The promotion of Beidou in the "Belt and Road" area can help these countries improve their location service capabilities and promote the application in medical, education, food safety, water security, public safety and other fields. At the same time, China's Beidou system accelerates the transition to civil use. In the process of promoting the civilian use of Beidou in countries along the "Belt and Road," a huge industrial chain will be formed, which will provide a huge impetus for the economic development of countries and regions along the "Belt and Road". To this end, we should implement the overall deployment according to our country's strategy for opening to the outside world. We need to be targeted to select countries that fall behind in the aspect of surveying and mapping geographic information to strengthen communication and consultation, understand the demands of assistance contents, and assistance methods and facilitate the signment of the memorandum of understanding and cooperation on surveying and mapping geographic information by the State Bureau of Surveying and Mapping Geographic Information and relevant government departments. We will focus on strengthening the foreign aid for surveying and mapping geographic information through market-based mechanisms, and guide relevant enterprises to become investment, execution, and revenue entities for surveying and mapping geographic information construction through popular business models such as BOT/PPP.

\subsection{Actively carry out mapping and geographic information} exchanges and international cooperation

In order to effectively promote the domestic advanced surveying and mapping geographic information technology and equipment to neighboring countries and regions, vigorously promote the internationalization of China's surveying and mapping geographic standards ,propel the mutual recognition of standards between China and the neighboring countries, and bring more technologies and products with independent intellectual property rights to the world by means of standardization, the surveying and mapping geographic information industry should strengthen international cooperation and exchanges, set up training centers or entrust colleges and universities to carry out foreign training and exchanges, and actively invite professionals in surveying and mapping geographic information field from neighboring countries and regions to come to China for training or study so as to radiate Surveying and Mapping Geographic Information Achievements from China to Other Countries. On the other hand, the surveying and mapping geographic information department should also apply for the establishment of a fund to strengthen education, training and scientific and technological cooperation in surveying and mapping geographic information with neighboring countries. With the support of science and technology departments and education departments, we should entrust universities or research institutions to set up Silk Road Remote Sensing Fund in the southwest and the western regions to provide financial support for surveying geographic information technology personnel in neighboring countries, college students and postgraduate students studying abroad. At 
the same time, in the western, southwestern and eastern coastal areas of China, we can make use of the regional advantages to form non-profit, regular and fixed-address international conference organizations to provide a high-level dialogue platform for surveying and mapping geographic information government, business leaders and well-known scholars in order to enhance the mutual understanding and exchange of Surveying and mapping information in related countries, deepen trade and investment ties and promote the establishment of partnership.

\section{REFERENCES}

Bohdan Vahalík, J., 2014a. 《Regional Bilateral Trade Analysis of the European Union, China and ASEAN 》 Procedia Economics and Finance, Vol.12.

Liu Ying, Ma Yurong. J., 2017a..."One Belt and Road" Embodies New Connotations of Globalization. Frontline Magazine, (5).pp.41-45.

National Defense Science, Technology and Industry Bureau, National Development and Reform Commission. 2016a."Guiding Opinions on Accelerating the Construction and Application of the "Belt and Road" Spatial Information Corridor".

Shen Xianjie, Xiao Jincheng. J., 2014a,The New Situation of International Regional Economic Cooperation and China's "One Belt and One Road" Cooperation Strategy.Macro Economic Research, (11):30-38. 